\title{
Network Analysis Functionality in Environmental Policy: Combining Abstract Software Engineering with Field Empiricism
}

\author{
N.D. Hasanagas
}

\author{
Nikolaos D. Hasanagas \\ University of Kavala \\ Institute of Technology Greece \\ E-mail:nikolaos.hasanagas@gmail.com
}

\begin{abstract}
An empirical application of abstract network analysis software is presented in this paper. Environmental policy networks are used as a case study. The visualization of the real network hierarchy and activity (formal and informal) is feasible only by using special software. A system of "actors" (e.g. public institutions, interest groups, enterprises) interacting with each other and dealing with a particular environmental issue constitutes a policy network, which influences the environmental policy functionality. The impacts of policy content ambiguity on network characteristics have been analyzed by using network analysis software as an example of combining algorithms with empiricism. Recommendations are made to software engineers about possible combination of algorithms with statistics and enrichment of the network analysis software with more visual analytic functions. Stronger familiarization of software engineers with policy analysis discourse and of policy analysts with positivism becomes more imperative for this purpose. On the basis of the quantitative results, environmental policy-makers are advised to invest more in trust development than in pressure and to instrumentalize more scientific information under conditions of ambiguity.

Keywords: Environmental Policy, Rural Development, Ambiguity, Network Analysis Software, Network Density.
\end{abstract}

\section{Introduction}

\subsection{Aims and orientation}

This research is presenting the results of an application of the software VISONE $[3,4]$ in the analysis and visualization of hierarchies and policy impacts.

The software alone is not able to be useful for analyzing practical policy issues, if the links of the network are not well defined and functionalized. This paper will show in details how software of social network analysis can be integrated into theoretical frameworks of policy analysis and in general will point out the importance of implementing software in the classical policy research in order to visualize and analyze the formal and informal hierarchies developed in policy making. The software engineers will improve the functionality of the software they develop, if they achieve to integrate it into the empirical implementation. For this purpose, they should cooperate with positivist social scientists and policy researchers.

The cases presented in this paper concern the impacts of legal acts which are characterized by ambiguous formulation. This paper is expected to interest policy makers and policy addressees (like associations of forest and land owners, environmental groups, enterprises, public agencies), as it provides information about obstacles they are going to confront with during their involvement in ambiguous environmental policy issues. Suggestions will be made for the improvement of their strategy. 
Basic features of the networks will also be presented. Methodological and theoretical points will be discussed.

\subsection{Literature review}

The need of abstracting social phenomena in a form of algorithm-based ontology has already been pointed out on numerous research occasions $[1,2,5,6,16]$. Such an abstract approach is a software tool for social network analysis. It is based on Matrix Algebra and can serve as an interdisciplinary tool for in-depth comparative exploration of different policy fields and issue networks in quantitative terms. In other words, it is a functionalization of the System Theory in the analysis of policy fields [7-11,32]. Through such a tool, the knowledge can be accessible for various learning communities $[15,17,23,25-30]$. However, an appropriate functionalization of the links of a network on an empirical basis is necessary. Otherwise, the abstract tool will remain interesting only for mathematicians or software engineers and it will not be applicable on particular policy fields.

The necessity for cooperation between software engineers and experts of particular fields, in order to integrate applicable algorithms in the software, has been acknowledged [19-21,33]. However, such joint projects could be many more than they are until now.

A policy network is a system of relations (exchange of information, trust, pressure) between actors (interest groups, enterprises and agencies), which deal with a particular policy issue (e.g. the certification of forestry sustainability in Denmark). What keep them together are the power relations between the actors $[8,13]$ and of course the hope of everyone -even of the weak ones- to gain something from their networking. The power is nothing but the ability of someone to get someone else doing something, even if this may be unpleasant for the latter. The political power can be distinguished in two main dimensions: a) trust and b) pressure. Pressure may be official or unofficial and is based on the institutional dependence which may be created in transparent or intransparent framework.

The dependence on material support is a weak dimension in the networks discussed in this paper [34], it presented no substantial correlation and will not be extensively examined on this occasion.

Trust usually causes the longest-term effects because it assures legitimization to the trusteeactor and keeps the behaviour of the trustor under control even when the trustee-actor is absent and cannot supervise the trustor (e.g. the client follows the advice of the attorney even outside his office). It is understandable that the power - more precisely its unequal distribution- builds formal and informal hierarchies in a network.

The sharper the oligarchy is within the network, the fewer the conflicts are, because normally none starts a conflict, when it is evident who is going to win. Under these conditions, the network is supposed to become more sustainable [24]. However, our results allow us discussing this hypothesis more critically; It is going to be shown that though high legal ambiguity decreases oligarchy and thus lets conflicts proliferate, the network is not dissolved. In contrast, the contacts between the actors proliferate and the more policy sectors are integrated within the network (e.g. tourism, forestry, agriculture, industry, urbanization and new relationship between urban and rural areas etc).

Another usual hypothesis which is here critically examined is that the trust between the actors is restricted, when the cross-sectorality of the network increases and the contacts between the actors proliferate $[13,16,31]$. Our finding supports that though sectors and contacts proliferate under conditions of high legal ambiguity, the trust relations also proliferate and are not deconstructed. In contrast, the relations based on pressure seem to be deconstructed.

It has been found that the use of general information (political arguments) is avoided as a 
mean of over-bridging sectors in networks which are characterized by high legal ambiguity ("low formalization degree") [12-14]. The hypothesis supported by our findings is that in case of high legal ambiguity the scientific information is more intensively used than the general one.

The findings will also support the hypothesis that the more non-regulative instruments (namely informative or financial means) are included in environmental policy content, the more ambiguous this content becomes [14].

\subsection{Paper's Innovation}

Even a software like VISONE which has been tested and proven to be appropriate for social network analysis, cannot be useful, if it is not integrated in an appropriate field-related theoretical and empirical framework. In this paper, the software VISONE is applied to forest environment policy networks by using Theory of Organized Interests. The "new relationship" between urban and rural areas can also be depicted on the interactions between interest groups and public institutions. The examination of the real (or not) "partnership" character of this relationship as provided by the European Spatial Development Perspective is also enabled.

It is an example of supporting abstract software with concrete empirical concepts. The results can be used as a feedback to software engineers as well as to policy analysts and power theorists (how network analysis software can be used for understanding policy arena hierarchies and their interaction with characteristics of policy content such as ambiguity). The innovation lies in the combination of empiricism and abstract software (Fig. 1).

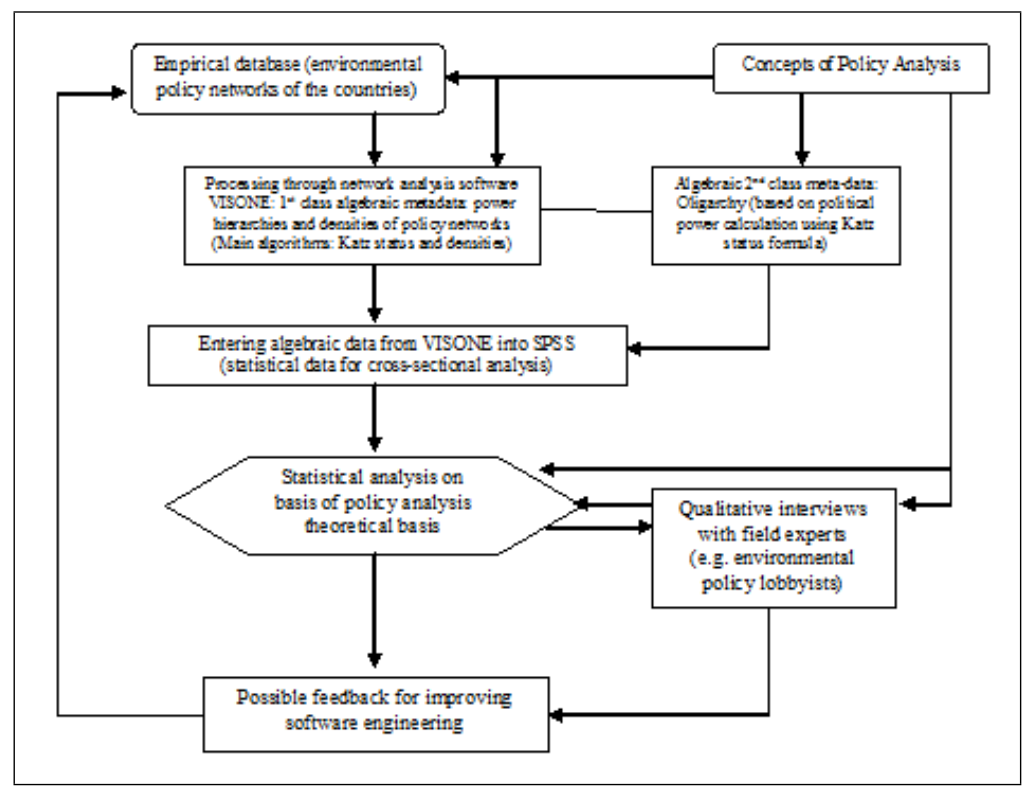

Figure 1: Supporting abstract software engineering with field research empiricism

\section{The Empirical Basis}

\subsection{Design of the empirical research}

Based on concepts of Policy Analysis such as power (trust and pressure), information, ambiguity, real policy networks are opened up in various countries and an empirical database is created. Then, the data are processed through VISONE software and statistics software SPSS 
considering concepts of Policy Analysis. Qualitative interviews serve as a corrective tool during the theoretical concept building and the interpretation or the quantitative findings (Fig. 1).

The data were selected from 12 networks of environmental policy throughout 8 countries of the European Union (they will be described below). Standardized questionnaires were used. The interviewees were chairpersons, general secretaries, lobbyists or managing directors of the actors. The first actor was randomly selected from a specific list and asked to mention an environmental issue (e.g. certification of sustainability in forestry), in which he was involved in the last two years and thought that he managed to be "successful". Then, he was asked to mention the actors with whom he came in contact, within the frame of the particular issue. Next, it was asked from these actors to report those actors that they came in contact with, within the frame of the same issue, as well, and so on. Through this snowball sampling, the whole network was structured step by step till it stopped getting expanded. This is the method of the complete network analysis. Then, it can be turned into a matrix and be processed algebraically and statistically. By using Matrix Algebra, it is possible to retrace the flow of information, of trust and of the pressure, and, thus, to find the individuals that can control most of the actors, revealing the true hierarchies (formal or informal).

The variables of VISONE were processed through cross-sectional analysis (Pearson test) at significance level of $5 \%$ after normality test. Pearson test is more flexible and functional, as it offers a clearer overview of correlations among variables, in contrast to other tests such as multivariate regression which may become more rigid and restrictive regarding variable relations. The network sampling which is applied is by definition a non-random sample. However, this is no methodological weakness as long as only analytic statistics (correlations between variables) is conducted and no generalization of descriptive statistical results (e.g. mean, variance) on a larger population is aimed. Qualitative interviews with field experts (lobbyists, directors etc) have confirmed the reliability of the quantitative results and help a deeper understanding of their perception and their causal relations, as will be discussed below (Section 3).

\section{$2.2 \quad$ Functionality \& Variables}

At first step, the details of the actor's identity are recorded so as to know whether he was a public or private one and the policy sector he is active in (agriculture, forestry, tourism, research, urbanization, etc.).

The hierarchy analysis of the network was based on the concept of oligarchy. The fewer the actors, which concentrate the power (pressure, trust), the higher the oligarchy becomes. The hierarchies are practically depicted in the form of chain control relationships: if the actor A gained actor's B trust, B gained C's trust and C gained D's trust and so on, then A could influence all: B, C and D, with just one call. Similar chains are formed in the case of pressure. An actor being on the top of numerous and longest chains, he has the highest power status in the network and he acquires the highest position in the hierarchy of the network. The previous power chains are calculated by a specific algorithm, the Katz status formula (Formula 1):

$$
T=a C+a^{2} C^{2}+\ldots+a^{k} C^{k}
$$

where $\mathrm{T}$ is a matrix including the status values of all actors as elements, $\mathrm{C}$ is the matrix presenting the real network (e.g. of trust links).

For that purpose a specific software (VISONE) is used, which visualizes this hierarchy, giving it the shape of a pyramid (Fig. 2). In this way, the actors are examined as objects comparable with each other and the networks can be clearly perceived as systems [23]. Thereby, the networks become also comparable with each other, independent of the different qualitative nature of the policy issues they concern. The position (status) of each actor in the vertical Y-axis of the 
pyramid is measured as power share (\%) the actor possesses. Actors that are found at the same level in the pyramid hold the same percentage. The more actors at the lowest level are, the larger is the bottom $\mathrm{X}$ of the pyramid, and, thus, a pyramid with a large base is shaped, which shows the existence of a high oligarchy (the horizontal layout of the actors at the various levels of the pyramid has nothing to do with their power).

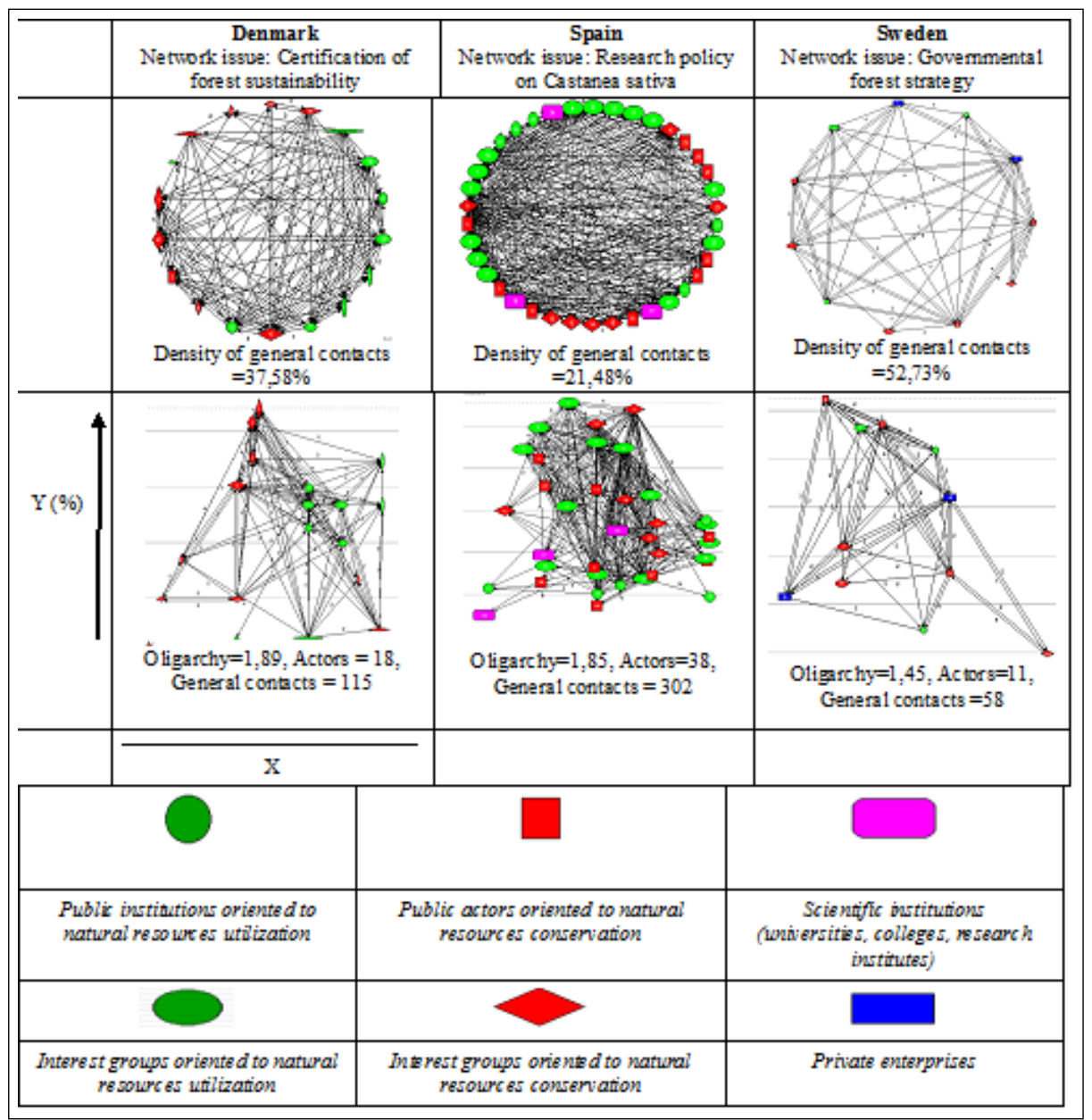

Figure 2: Examples of environmental policy networks by VISONE

The oligarchy of every network was set as the difference between the maximum (max) and the minimum ( $\mathrm{min}$ ) power value (status) that appeared in each network divided by the average power of all actors of the network and it may vary from 0 till infinity (Formula 2) [21]. Oligarchy is a meta-data derived from power and it is not measured any more as $\%$ but as a pure number. Thus, it is a mono-dimensional (single-number) indicator of the politico-administrative structure. More precisely, the links of trust and the links of pressure are primary data. The power calculated with Katz status formula is $1^{\text {st }}$ class meta-data and the oligarchy which calculated using power status is a $2^{\text {nd }}$ class meta-data [27-30].

$$
\text { Oligarchy }=\frac{\text { Status max }- \text { Status min }}{\text { Status Average }}
$$

Another variable is the density of the links (general contacts, conflicts, trust, pressure, exchange of general or scientific information). This variable becomes visually clear in the polygonal form of the networks in Fig. 2. If every relation is regarded as a diagonal, then the density ex- 
presses the percentage of the existing diagonals divided by the total number of all possible diagonals of the polygon (Formula 3 ). Thus, density is a $1^{\text {st }}$ class meta-data based on the links number (primary data) of a particular relation type (trust, conflicts etc). In fact, high density practically means that every chance of cooperation (or conflict) within the network has been explored and used at highest possible level.

$$
\text { Density of relation } A=N \text { umber of links of relation } A /\left(N^{2}-N\right)
$$

where $\mathrm{N}$ is the number of actors participating in the network.

In general, Katz status and oligarchy provides insights about the real structure (formal and informal) of the network, about the power concentration and thereby about the coordination potential, while the density is suitable for the diagnosis of the intensity of the activity and the importance of each type of relation (general contacts, conflicts, trust, pressure, general or scientific information) for the network cohesion as well as about the saturation of policy activity (e.g. lobbying) within a network (Fig.3).

\begin{tabular}{|l|l|l|}
\hline \multicolumn{1}{|c|}{$T_{\text {vpe of data }}$} & \multicolumn{1}{|c|}{ Structure } & \multicolumn{1}{c|}{ Activity } \\
\hline Primary data (links) & - trust & - general contacts \\
& - pressure & - conflicts \\
& & - trust \\
& & - pressure \\
& & information (general \\
& & or scientific) \\
& & Density \\
\hline$I^{12}$ class meta-data & Katz status & - \\
\hline $2^{\text {rs }}$ class meta-data & Oligarchy & \\
\hline
\end{tabular}

Figure 3: Data classification

Apart from the general contacts that are detected, more specialized relations were measured by means of the following questions:

- Trust:

To what extent would you let each of the following actors, with whom you came in contact with, to make a decision on behalf of you or you would follow their suggestions without examining them critically? 1: there is no such possibility, 2: partly, 3: to the hilt

- Institutional pressure:

Tell us for each actor, that you came in contact with, whether he was irreplaceable for you, because of a specific function he had, in the particular issue. 0: no, 1: yes

- General information:

Tell us from what actor you received information (of any kind). 0: if no information was received, 1: if there is information flow.

- Scientific information:

Name three actors from whom you received the most important scientific information. This relation was scaled with 0 and 1 , as in the case of the general information.

- Conflict:

Name the actors you were in conflict with. This was scaled with 0 and 1.

- Ambiguity of policy content: 
Tell us how often you needed interpretation of the laws and other rules concerning the particular issue, you were involved in, from a solicitor or other experts. 1: not at all, 2: sometimes, 3: very often. The average of the grades that the actors noted in a network showed the general ambiguity of the policy content of network issue (Fig. 3).

- Interventionism:

It has been calculated as the inverse of the ambiguity. Since the ambiguity varies from 1 to 3 , the legal interventionism varies respectively from 1 to 0,33 . It just constitutes a subsidiary indicator for technical-statistical reasons, which presents a significant correlation with crosssectorality and is presented as an alternative indicator.

\section{The Case study: Meta-Information of Functionality}

\subsection{Networks analysis}

The 12 environmental policy networks are the following ones:

I) In Denmark a network of 18 "actors", concerning the certification of sustainable management of natural recourses was explored. This issue treated the enactment of specifications and control processes about the management of natural resources, so that their production potential will not be degraded. Network of the same issue (sustainability of natural resources) was opened up in II) Finland (24 actors) and in (III) Spain (38 actors). IV) In Bavaria, a network of 14 actors was opened up, which was concerning "the eco-account", namely the evaluation and the counterbalance of environmental consequences. V) Moreover, in Bavaria another network of 16 actors was opened up, which dealt with the mapping and description of forest biotopes. VI) In Sweden, a network related to the protection of biotopes (11 actors) and one more VII) related to the national forest policy (14 actors) were explored. VIII) In Greece, a network of 13 actors concerning the Article 24 of the Constitution was opened up. IX) In Scotland, the network was related to the forest policy (23 actors) and X) to the issue of the national park Loch Lomond and Trossachs (27 actors). XI) In Ireland, a network related to the provisional marketing services in forestry was examined (25 actors) and XII) in Spain, a network concerning research on Castanea genetics (21 actors) was analyzed.

All 12 networks involved 234 actors in total: 30\% public agencies and 70\% private actors. According to their function they can be categorized as follows: a) $43 \%$ interest groups which deal with the economic utilization of natural resources (unions of enterprises, forest industries and landowners), b) $42 \%$ actors aiming at nature conservation (e.g. institutions of environmental protection, environmental organizations), c) 6\% individual enterprises (not unions of enterprises), d) $9 \%$ scientific actors (universities, research centers). In all these issue networks forest policy and rural development matters are strongly interconnected and are included in the wider field of the environmental policy discourse.

\subsection{Consequences of ambiguity}

Hypothesis 1

As the ambiguity increases, and the hierarchy (oligarchy) dissolves, and consequently the conflicts increase, the networks not only do not dissolve but in contrast, the contacts between the actors and the cross-sectorality increase.

In Table 1, there is a significant positive correlation between ambiguity, density of conflicts and density of general contacts. The cross-sectorality has a reciprocal relation with the legal interventionism, so practically it could be assumed that it increases with the ambiguity $[12,18,31]$. 
The more ambiguous the policy content is, the more disagreements appear about the obligations and rights of the actors and about which measures or specifications should be further institutionalized: Who will pay compensations for any restrictions imposed on natural resource utilization? What authorizations should the interest groups have? Which "risk" should be considered to be "acceptable"? etc. Such questions are steadily posed in case of ambiguous lawmaking. Under these conditions, the probability of conflict becomes higher. The only antidote would be a clear law. If the law is explicit enough from the beginning, it becomes clear who can participate in the network, and what he is expected or allowed to do.

As mentioned above, the fact that the networks dissolve, when the conflicts increase, is frequently supported. However, in Table 1, it is observed that apart from the conflicts that become denser to ambiguity $(0,168)$, the general contacts among the actors become much denser $(0,557)$. It is thus understandable that in truculent and uncertain political-administrative conditions, the actors try to broaden their coalitions in order to outbalance the chances which are lost or new threats created because of conflicts. Therefore, more and more opportunities of collaboration are used and the network is sustained, despite the increasing conflicts. Thus, the software proves that the policy networks have retroaction mechanisms.

In Table 1, it is also evident that the cross-sectorality is further developed, as the state intervensionism (inverse of ambiguity) decreases $(-0,132)$. Actors from many different sectors can interpret the abstract aims and restrictions of a policy content, in such a way that they seem to be in accordance with their interests and capacities. An ambiguous law about the "protection of mountain water resources" makes possible the involvement of a wide spectrum of actors: from environmental organizations up to unions of construction firms, but also fresh water enterprises or angling tourism business. Of course, this may cause a proliferation of conflicts but without putting the network at risk.

In Table 1, the oligarchy decreases as the ambiguity increases $(-0,441)$ (namely, the form of the pyramid becomes unclear, see Fig. 1). The decrease of oligarchy gives a free scope to conflicts because it is less evident who is going to win. Thus, anyone -even the weak ones- find the courage to risk a controversy. The dissolution of hierarchy is the result of the fact that it is not clear who controls whom.

Table 1. Consequences of ambiguity in conflicts, in the density of general contacts, in cross-sectorality and in oligarchy

\begin{tabular}{|c|c|c|}
\hline & & Ambiguity \\
\hline Density of conflict-relations & Pearson Coefficient & .168 \\
\hline & Level of significance & .010 \\
\hline Density of general contacts & Pearson Coefficient & .557 \\
\hline & Level of significance & .000 \\
\hline Oligarchy (official and unofficial hierarchies) & Pearson Coefficient & -.441 \\
\hline & Level of significance & .000 \\
\hline Cross-sectorality (number of involved political sectors) & & Pearson Coefficient \\
\hline & Level of significance & -.132 \\
\hline
\end{tabular}

Hypothesis 2

Under high ambiguity conditions (even if the general contacts get denser and there is high crosssectorality and uncertainty in the network, as supported in Hypothesis 1), the trust relations proliferate, while the relations of pressure decrease.

The common belief is that under high ambiguity, the contacts proliferate in a network, and consequently the trust is reduced, as the potential sources of difference and threats increase and 
it becomes more difficult for a larger number of participants to become familiar enough with each other and to build clear and well coordinated coalitions. However, as seen in Table 2, when the ambiguity increases, the trust seems also to increase $(0,242)$. Simultaneously, there seems to be a minimization of the usage of pressure $(-0,407)$. This happens because it is not clear when, how and who can activate a regulative coercive tool. Therefore, trust becomes a more preferable politico-administrative power form than pressure.

When some actors provide convincing interpretations, then they gain the trust of the rest actors. Inversely, actors, who have already gained the trust of others, thanks to their multidisciplinary staff and their stable and lawful behavior have better chances to present their interpretations as more convincing [11,13, 18, 22, 24,31].

Apart from that, in a network of high ambiguity a kind of "natural selection" also takes place; from the very beginning the only actors who survive are rather the reliable actors. Thus, in such a network it is more crucial for an actor to gain the trust of the others and satisfy his interest than to try to exert pressure "in the name of" an ambiguous rule with unknown results. It could be assumed that under conditions of high ambiguity, the anxiety derived from the uncertainty of the interpretation surpasses the anxiety of a new coalition. For this reason, trust can be developed.

Table 2. Consequences of ambiguity in the composition of power (trust and institutional pressure)

\begin{tabular}{|c|c|c|}
\hline & & Ambiguity \\
\hline Density of trust relation & Pearson Coefficient & .242 \\
\hline & Level of significance & .000 \\
\hline Density of relations of pressure & Pearson Coefficient & -.407 \\
\hline & Level of significance & .000 \\
\hline
\end{tabular}

Hypothesis 3

As the ambiguity increases, the use of scientific information increases, while the use of general information is restricted.

As seen in Table 3, the ambiguity creates a "friendly" or even attractive environment for the experts (lawyers, planers etc), since the need of using scientific information increases $(0,250)$ at the expense of general information $(-0,329)$ which can be used by any lobbyist, even by those who are not considered to be "specialized" in the particular policy issue. Because of the need of actors to be adjustable to the steadily developing "new technologies" and to the socio-political and economic changes, both expert ("scientific") knowledge on legal matters and non-legal rules (e.g. norms of nature, technology, and marketing) is demanded. Therefore, the contribution of a wide range of scientists (solicitors, archeologists, biologists etc) is indispensable, and information which is regarded as "scientific" proliferates.

As the ambiguity increases, the use of general information (matters of organizing, politics and administration) is reduced. In ambiguous issues, one expects from the scientists to play more important and intensive role in comparison with the director of public relations and the administration staff. In contrast, administrative staff can solve problems only by using formalized procedures expressed through general information and not by developing "scientific" creativeness.

Table 3. Policy impacts of ambiguity in general and scientific information

\begin{tabular}{|c|c|c|}
\hline & & Ambiguity \\
\hline Density of scientific information & Pearson Coefficient & .250 \\
\hline & Level of significance & .000 \\
\hline Density of general information & Pearson Coefficient & -.329 \\
\hline & Level of significance & .000 \\
\hline
\end{tabular}


Hypothesis 4

When a policy measure is not a direct (regulative) instrument (threat of penalty) but an indirect (economic or informational) instrument (motivating or convincing), then it is more ambiguous.

In Table 4, it is evident that the pressure from the public actors towards the private ones, which is the basis for implementing regulative tools that necessitate clear rules, tends to decrease under conditions of high ambiguity $(-0,140)$. Ambiguity tends to appear in policy contents which include indirect instruments. Example of indirect instrument is a law which encourages the use of anti-pollution technology via the award of an ecological badge. The ambiguity of the indirect instrument is derived from the wide range of possible interpretations concerning the forms of "environment-friendly" attitude, the standards, the form, the procedure and the source of the reward (e.g. environmental tax, compensation for restrictions on the exploitation of natural resources, award of an ecological badge) and the procedure of performance assessment.

In Table 4, an increase of the number of contacts from the part of private actors towards the public ones (chances of lobbying) is also observed $(0,146)$ under conditions of high ambiguity. This can be explained by the need of private actors to receive clear and reliable information about the law implementation. Thus, ambiguity can become a basis for new obstacles but also for new lobbying and collaborations but also between public and private actors.

Table 4. Consequences of ambiguity in the relations of public-private sector and in the institutional pressure of public actors

\begin{tabular}{|c|c|c|}
\hline $\begin{array}{c}\text { Number of relations of pressure exercised by public } \\
\text { actors to private actors }\end{array}$ & Pearson Coefficient & Ambiguity \\
\hline & Level of significance & .140 \\
\hline $\begin{array}{c}\text { Average of general contacts from the private actors } \\
\text { towards the public ones }\end{array}$ & Pearson Coefficient & .146 \\
\hline & Level of significance & .026 \\
\hline
\end{tabular}

\section{Conclusion \& Discussion}

A software toolbox which is engineered for social network analysis can be useful for analyzing policy issues and politico-administrative systems as multi-objective entities (different types of links, hierarchies and actors). It may be applicable in improving power status, policy implementation and lobbying as well as in policy e-learning systems for lobbyists and administrators (e.g. using networks as role play scenarios). Such a software product is purposeful for detecting the real hierarchies and activities (not only the formal but also the informal ones).

Basic points for software engineers and policy analysts are the following ones:

The visualization is especially useful for this purpose. The algorithm of Katz status seems to be a useful tool, as it has been proven not only to be useful for visualizing hierarchy but also to visualize political oligarchy, at least according to the definition employed in this paper. The oligarchy indicates the potential of politico-administrative coordination. Apart from that, the oligarchy concept which is based on the power calculation and the density of trust, pressure, information and conflicts presented field-related properties such as statistical correlation with policy content ambiguity.

Another useful algorithm which presented properties interesting for policy-makers and policy analysts is this of density of various types of links, which practically indicates intensity of activity. As these properties are detected through statistical analysis, software designed for social network analysis can become more efficient, if it includes statistical functions, particularly tests, or if it provides the possibility of exporting output data to statistical software or to convert them in other 
types of files which should be importable to statistical sheets. In any case, statistical analysis can hardly be isolated from social network analysis, if useful properties of social network are expected to be found. Therefore, social network analysis software should offer combined functions of Matrix Algebra and Statistics.

An additional technical advantage could be to offer the possibility of appearance of each type of links in different color within the same network file. In this way, it would be possible to visually distinguish trust from pressure links and to comparatively examine the hierarchy of trust and this of pressure within the same pyramid. Similarly, a visual comparison of different densities (trust, scientific information, general information etc) would be possible.

Before starting primary data collection and meta-data definition, the software should be integrated in theoretical frameworks of Policy Analysis and empirical research design. Without a precise definition and measurement of each type of links (e.g. trust, pressure), the quantitative metadata of such software toolbox will have no meaning for the policy field they are applied to and will not be convincing researchers and experts of empirical disciplines. Thus, a systematic collaboration between software engineers, policy analysts and policy field experts is necessary. For this purpose, software engineers should maintain narrow contact to policy analysis discourse and policy analysts should adopt more positivism.

Basic conclusions for policy-makers could be the following ones:

Although ambiguity increases the conflicts among the actors, it does not dissolve the network but increase the cross-sectorality and it lets the contacts proliferate. Moreover, it prevents the development of strict hierarchies based on pressure and favors the development of trust. In this way, it may contribute to the development of more sustainable collaborations, as trust is effective even without surveillance. In contrast, the use of pressure does not seem to be effective under conditions of ambiguity. Using information which is regarded as "scientific" is also an effective strategy. Interest groups of forest and landowners etc should pay extra attention to this point because they are normally characterized by restricted multidisciplinarity in comparison with the environmental organizations and thus, they have a more restricted persuasion potential in comparison with the environmentalists.

Actors involved in ambiguous issues must be especially well prepared for a lot of disagreements and conflicts. The role of "peacemaker" can be adopted by anyone who can gain the trust of the others and will not try to implement a forced "peace" that "suits" his interests through pressure. The successful lobbying of a private actor to the public actors is of major importance in order to assure access to explicit instructions. Ambiguous policy contents do not only cause difficulties but can also provide opportunities of satisfying interests and building new coalitions. The need for an apt and long-term lobbying becomes more imperative in the case of indirect (economic and informational) instruments, which tend to be characterized by higher ambiguity than the direct (regulative) instruments.

\section{Acknowledgements}

The research initiative proposed by this paper has been supported by the Department of Landscape Architecture, Kavala Institute of Technology, Drama, Greece), and by the Institute of Forest Policy and Nature Conservation of Goettingen University (Germany).

\section{Bibliography}

[1] D. Arotaritei, Genetic Algorithm for Fuzzy Neural Networks using Locally Crossover. Int. J. of Computers Communications \& Control, ISSN 1841-9836, 6(1): 8-20, 2011.

[2] I. Dzitac, B.E. Bărbat, Artificial Intelligence + Distributed Systems = Agents. Int. J. of Computers Communications \& Control, ISSN 1841-9836, 4(1): 17-26, 2009. 
[3] M. Baur, M. Benkert, U. Brandes, S. Cornelsen, M. Gaertler, B. Koepf, J. Lerner, D. Wagner, VISONE - Software for Visual Social Network Analysis. Porc. 9th Intl. Symp. Graph Drawing, Lecture Notes in Computer Science, Springer, 2265: 463-464, 2002.

[4] U. Brandes, P. Kenis, D. Wagner Communicating centrality in policy network drawings. IEEE transactions on visualization and computer graphics 9(2), 241-253, 2003.

[5] P. Dolog and W. Nejdl, Challenges and Benefits of the Semantic Web for User Modelling. Workshop on Adaptive Hypermedia and Adaptive Web-Based Systems, In Proc. of the $12^{\text {th }}$ International World Wide Web Conference, Budapest, Hungary, 2003.

[6] P. Dolog, N. Henze, W. Nejdl and M. Sintek, Personalization in Distributed eLearning Environments. In Proc. of the $13^{\text {th }}$ International World Wide Web Conference, New York, USA, 2004 .

[7] N.D. Hasanagas, Implications of the Europeanization in Trans-sectoral Environmental Policy Areas. Case study: Forestry and Nature Conservation. Interdisciplinary Environmental Review, 3(2): 118-133, 2001.

[8] N.D. Hasanagas and R. Shoesmith, The role of the European Parliament in forest environment issues. European Environment, 12: 213-223, 2002.

[9] N.D. Hasanagas, A. Sachpazi, S. Kamkos, G. Tzimpridou, P. Birtsas and K. Radoglou, Quantitative analysis of socio-political power and structures in hunting-environmental policy networks. An application of Mathematical Sociology to the Environmental Policy Analysis. National Agriculture Research Foundation, Dept. of Publications. Athens-Thessaloniki, 2009.

[10] N.D. Hasanagas, A.D. Styliadis, E. Papadopoulou and L. Sexidis, E- Learning E Environmental Policy: The case of a politico-administrative GIS. Int. J. of Computers, Communications \& Control, 5(5): 517-524, 2010.

[11] N.D. Hasanagas, A.D. Styliadis and E. Papadopoulou, Environmental Policy $\&$ Science Management: Using a scientometric-specific GIS for e-learning purposes. Int. J. of Computers, Communications \& Control, 5(2): 171- 178, 2010.

[12] N. Intzesisoglou, Sociology of Law - Epistemological discussion: The subject the Sociology of Law and its role in the Law Science (orig. Greek). Vol. I. Publisher Sakkoula. Thessaloniki, 1990.

[13] M. Krott and N.D. Hasanagas, Measuring bridges between sectors: Causative evaluation of cross-sectorality. Forest Policy and Economics, 8, 555-563, 2006.

[14] E. Koutoupa-Regkakou, Environmental Law (orig. Greek). Publisher Sakkoula. Thessaloniki, 2005.

[15] G. McCalla, The Fragmentation of Culture, Learning, Teaching and Technology: Implications for the Artificial Intelligence in Education Research Agenda in 2010. International Journal of Artificial Intelligence in Education, 11: 177-196, 2000.

[16] M. Medjoudj and P. Yim, Extraction of Critical Scenarios in a Railway Level Crossing Control System. Int. J. of Computers, Communications \& Control, 2(3): 252-268, 2007.

[17] P. Mohan, J. Greer and G. McGalla, Instructional Planning with Learning Objects. Workshop on Knowledge Representation and Automated Reasoning for E-Learning Systems. In Proc. Of the $18^{\text {th }}$ International Joint Conference on Artificial Intelligence, Acapulco, Mexico, 2003. 
[18] Th.K. Papachristou, Sociology of Law (orig. Greek). Publisher Sakkoula. Thessaloniki, 1999.

[19] P.R. Polsani, Use and Abuse of Reusable Learning Objects". Journal of Digital information. Retrieved in September 2005 from the World Wide Web: http://jodi.ecs.soton.ac.uk/Articles/v03/ i04/Polsani, 2003.

[20] M.A. Rajan, M. Girish Chandra, L.C. Reddy and P. Hiremath, Concepts of Graph Theory Relevant to Ad-hoc Networks, Int. J. of Computers, Communications \& Control, ISSN 18419836, 3(S): 465-469, 2008.

[21] A. Real and N.D. Hasanagas, Complete Network Analysis in Research of Organized Interests and Policy Analysis: Indicators, Methodical Aspects and Challenges. Connections 26(2), 89106, 2005.

[22] H. Simon, Decision-making in organizations. Berlin, 1978.

[23] M. Stanojevi'c, M. Vujosevi'c and B. Stanojevi'c, Number of Efficient Points in some Multiobjective Combinatorial Optimization Problems. Int,. J. of Computers, Communications \& Control, ISSN 1841-9836, 3(S): 497-502, 2008.

[24] C.N. Stone, Systemic power in community decision-making: A restatement of stratification theory. In: The American Political Science Review, V.74, 978-90, 1980.

[25] A.D. Styliadis, Digital documentation of historical buildings with 3-d modeling functionality. Automation in Construction 16, 498-510, 2007.

[26] A.D. Styliadis, E-Learning Documentation of Historical Living Systems with 3-D Modeling Functionality. INFORMATICA, 18(3), 419-446, 2007.

[27] A.D. Styliadis, Historical photography-based computer-aided architectural design: Demolished buildings information modeling with reverse engineering functionality. Automation in Construction 18, 51-69, 2008.

[28] A.D. Styliadis, D.G. Konstantinidou and K.A. Tyxola, eCAD System Design - Applications in Architecture. Int. J. of Computers, Communications \& Control, 3(2): 204-214, 2008.

[29] A.D. Styliadis, P.G. Patias, N.C. Zestas, 3-D Computer Modeling with Intra- Component, Geometric, Quality and Topological Constraints. INFORMATICA, 14(3), 375-392, 2003.

[30] A.D. Styliadis, I.I. Akbaylar, D.A. Papadopoulou, N.D. Hasanagas, S.A. Roussa, L.A. Sexidis, Metadata-based heritage sites modeling with e-learning functionality. Journal of Cultural Heritage 10, 296-312, 2009.

[31] I. Tsivakou, The flexible boundaries of the social systems. Publisher Nefeli. Athens, 2003.

[32] M.S. Urban and E.G. Barriocanal, On the Integration of IEEE-LOM Metadata Instances and Ontologies. Learning Technology Newsletter, Vol. 5 (1), 1-4, 2003.

[33] H. Wu and P. De Bra, Suficient Conditions for Well-behaved Adaptive Hypermedia Systems. In Proc. of the First Asia-Pacific Conference on Web Intelligence: Research and Development, Maebashi City, Japan, 2001.

[34] N.D. Hasanagas, Power Factor Typology through Organizational and Network Analysis. Using Environmental Policy Networks as an Illustration. Publisher Ibidem. Stuttgart, 2004. 